\title{
SOBRE ANTROPOLOGIA POLITICA (DIALOGO POLEMICO CON UN VIEJO DISCURSO)
}

Enrique Luque Baena

\section{Introducción}

Quiero aclarar que no pretendo ocuparme aquí de definir términos como político o política. Si acaso, mi preocupación se mueve en dirección opuesta. Por ello, a lo largo de estas páginas apuntaré a los problemas que entraña la empresa misma de definir una y otra noción y a algunos no muy fructíferos intentos de delimitar sus ámbitos.

Desde mi punto de vista, lo que hoy se llama antropología política constituye no tanto una disciplina o una especialización cuanto algo diferente: una etapa (no diré que final) de un largo e intrincado proceso. Una etapa que, más que a reforzar el discurso del filósofo o del científico de la política, viene a trastocar alguno de sus cimientos más férreos y más queridos. Pero esa especie de labor traumática parece ineludible si queremos dotar de dimensión humana aquel discurso

He aquí el primer problema que plantea la antropología política: del espacio reducido (físico y humano) que alumbró el término político hemos dado el increíble salto que nos sitúa hoy en un espacio sin fronteras. Porque no está de más recordar que el significado primero de la palabra pólis no era -incluso en tiempos históricos- equivalente al de ciudad, sino al más ar- 
caico de ciudadela, de fortaleza. De akrópolis, en definitiva'. Sólo los etólogos llevan camino de superarnos: ya vienen hablando hace algún tiempo del comportamiento político de nuestros parientes simiescos. $\mathrm{Y}$ todo ello sin abandonar el nombre que engendró la fortaleza helénica.

Pero el término no ha pervivido, claro está, impunemente. Lo que ha ganado en extensión lo ha perdido en intensidad. El costo de la transformación ha sido elevado. Pero el precio lo han pagado gustosamente muchos filósofos y científicos de la política. Y, por supuesto, también un buen plantel de antropólogos contemporáneos. Sin embargo, otros se han mostrado más que reacios a abandonar algo fundamental que encerraba el significado prístino de lo político. Marcel Mauss, por ejemplo, como espero hacer ver al final de este trabajo ${ }^{2}$. Pero puedo adelantar ya que, en el caso de Mauss, el costo ha sido otro: la indelimitación del ámbito político. Algo que, sin duda, puede llenar de enojo a los obsesionados por las definiciones preliminares.

Porque Mauss, al ampliar, como otros antropólogos, el universo político mucho más allá de la pólis, se ha negado — como pone de relieve Marshall Sahlins ${ }^{3}$ - a discutir la génesis estructural de la vida social en términos convencionalmente políticos. $\mathrm{Y}$ donde Hobbes pone el Estado como resultado necesario del pacto o contrato social, Mauss pone el intercambio. Como telón de fondo tenemos, en ambos casos, la guerra: Hobbes pretende suprimirla gracias al Leviatán (que, situándose por encima de los probables contendientes, da seguridad al atribulado burgués a cambio de una buena parcela de su libertad). Mauss, nos viene a decir Sahlins, lee hobbesianamente el discurso de la guerra primitiva, y, sin embargo, el tipo de contrato que de ella resulta tiene, en Mauss, mucho más de Rousseau que de Hobbes. La guerra de todos contra todos se convierte en el intercambio de todos con todos cuando de los pueblos primitivos o arcaicos se trata. Una gran parte de la humanidad nos enseña que la guerra no es la antítesis de la sociedad y que su supresión, siquiera sea temporal, no tiene que llevar aparejada la renuncia a la libertad de los pactantes. Este es el mensaje más profundo del «Ensayo sobre el don», el regalo del regalo. Aunque no el único, como luego veremos.

El potlatch (del cual recalca Mauss su naturaleza agónica) no viene a ser sino una suerte de guerra sublimada. Leviatán, podríamos añadir, supone la suprema consagración de la beteronomía. El intercambio (festivo, aparentemente inútil y muchas veces destructor) conlleva, por el contrario, el mayor grado de autonomía de las partes.

${ }^{1}$ Emile Benveniste, Le vocabulaire des institutions indo-européennes, París, Les Editions de Minuit, vol. 1, p. 367, 1969.

${ }^{2} \mathrm{Me}$ refiero a su "Essai sur le don. Forme et raison de l'échange dans les sociétés archaïques", publicado originariamente en L'Année Sociologique (19231924) y compilado con otros trabajos de Mauss en el libro Sociologie et anthropologie, París, P.U.F., pp. 143-279, 1978 (e. o. 1950).

${ }^{3}$ Marshall Sahlins, "The Spirit of the Gift", en Stone Age Economics, Londres, Tavistock, pp. 149-183, 1974 (e. o. 1972). 
Creo que con esto tenemos planteado el problema: la filosofía y la ciencia políticas han seccionado una esfera de la vida. Se diría que la teoría política ha ido ganando en claridad a la par que los súbditos perdían autonomía. Algunos antropólogos - pero no todos, como luego veremos- parecen haber seguido el camino opuesto: queriendo comprender realidades otras (donde la absoluta heteronomía aún no se había entronizado), se han visto obligados a prescindir de la nitidez conceptual. Lo cual, entre otras cosas, les ha valido el palmetazo aleccionador e indiscriminado de David Easton, quien hace ya años afirmaba que no existía ni existiría antropología política hasta que no se hubieran resuelto serios problemas conceptuales. Ante todo, cómo diferenciar lo político de lo no político ${ }^{4}$.

Sin embargo, hay, por así decirlo, un triángulo en el que coinciden antropólogos y no antropólogos. Sus vértices son la guerra, el pacto y el orden político. El desarrollo de la antropología viene a ser, a través de él, un diálogo continuo -a veces crispado y muchas veces clandestino- - con la filosofía y la ciencia políticas. Dejémoslo, de momento, y volvamos a algo que tan sólo he sugerido.

\section{Las dos grandes concepciones de la política}

Jürgen Habermas ha puesto de relieve cómo la vieja concepción de la política, la que alumbró la pólis, se nos hace ajena y extraña a partir de la revolución conceptual que inicia Maquiavelo y completa Hobbes ${ }^{5}$. Veamos, de la forma más breve posible, en qué consiste la gran transformación a la que se refiere Habermas.

En la concepción clásica y aristotélica, la política se considera un arte (esto es, una práctica y no una técnica), que no puede equipararse a una ciencia rigurosa. Y ello porque su objeto, lo Justo y Excelente, carece de constancia ontológica y de necesidad lógica. Como parte de la filosofía más práctica que es, la política se basa en la phronesis, en el entendimiento prudente de la situación. Además, no hay ni puede haber discontinuidad entre ética y política, entre el ámbito privado y el ámbito público, porque ser humano y ser ciudadano es una y la misma cosa: ser un zoon politikon.

En la concepción hobbesiana, por el contrario, la política se ha convertido ya en una técnica, científicamente fundamentada, cuyos postulados son válidos con independencia de todo contexto espacial y temporal. Si se posee un conocimiento del orden correcto del Estado y de la sociedad, ya no se requiere la acción prudente (práctica) de los seres humanos en sus mutuas relaciones. Lo que sí se requiere, por el contrario, es la producción correctamente

" "Political Anthropology", Biennial Review of Anthropology, vol. 1, pp. 210216, 1959.

sheory and Practice, Boston, Beacon Press, pp. 41 y ss., 1973 (e.o. 1963). 
calculada de reglas, relaciones e instituciones. La conducta humana deviene, así, mero material científico, como los objetos de la naturaleza, susceptible de ser moldeada por los ingenieros del orden social y al margen de toda consideración ética.

No puedo detenerme a valorar aquí los contrastes que establece Habermas ${ }^{6}$. Aceptemos que, en líneas generales, son válidos para marcar los rasgos antitéticos de dos grandes concepciones del pensamiento político occidental, surgidas de la reflexión acerca de la pólis griega y del Estado-nación europeo. Vistas así las cosas, la revolución hobbesiana representa la transformación que va a hacer posible, a la larga, una ciencia política y una antropología política, en el sentido contemporáneo del término. Las murallas de la fortaleza helénica se derrumban definitivamente con la obra de Hobbes (cuyo propósito, como han recalcado sus estudiosos, es extender al campo de los fenómenos políticos la revolución que Galileo ha llevado a cabo años antes en el de los fenómenos físicos).

Pero no hay que olvidar que Hobbes reduce, pese a todo, lo político a lo estatal. Sin pretender en absoluto atribuir a los filósofos del siglo xvir lo que es fruto de una reflexión muy posterior (esto es, la noción de evolución sociocultural), cabría afirmar, no obstante, que para Hobbes la humanidad se divide en dos bloques: la que vive en estado de naturaleza y la que, mediante el pacto social, alcanza la República (la civitas). Pero hay advertir enseguida que no se trata ni de etapas evolutivas ni de distribución geográfica. Frente al conocido argumento aristotélico de la sociabilidad natural (la que ejemplifican abejas y hormigas), Hobbes lanza toda una batería de contraargumentos para demostrar lo peculiar de la condición humana. Merece la pena mencionar el sexto y último:

«Por último, el acuerdo de esas criaturas es natural, y el de los hombres proviene sólo de pacto, lo cual implica artificio. En consecuencia, no debe asombrar que (además del pacto) deba existir algo capaz de hacer constante su acuerdo, esto es, un poder común que los mantenga en el temor y dirija sus naciones al beneficio común.»

Desaparecido ese poder común (dirá Hobbes al estudiar la disolución de la República por guerra exterior o intestina), «cada hombre está en libertad para protegerse por los medios que su propia discreción le sugiera» ${ }^{7}$. Dicho de otro modo: hay que apuntalar bien el edificio, el artificio, porque el proceso es temiblemente reversible en cualquier momento y en cualquier lugar.

- Aunque si habría que apuntar que, según los estudiosos de la obra aristotélica, tales caracteres, presentes sin duda en La politica. corresponden, más que al realismo aristotélico, a la concepción más tradicional y más antigua, la del maestro y antagonita Platón. Véase la Introducción de Carlos García Gual a la edición de Editora Nacional, Madrid, 1977.

'Leviatán, Madrid, Editora Nacional, pp. 266 y 406 (cursiva, mía), 1979. 
Que la solución hobbesiana sea el poder absoluto (de un solo hombre o de una asamblea) tiene menos trascendencia para la universalización del discurso político que el haber apuntado a la siempre posible reversibilidad del proceso. Esto es precisamente - como ha insistido Sahlins- lo que hace al pensamiento hobbesiano mucho más interesante para la antropología política contemporánea de lo que muchos sospechan. Y, sin embargo, antropólogos y no antropólogos parecen haber prestado mucha más atención a una magra referencia etnográfica («las gentes salvajes de muchos lugares de América») que aparece en el famoso capítulo XIII de Leviatán, capítulo que trata, precisamente, "De la condición natural del género humano, en lo que concierne a su felicidad y miseria». Tal referencia es casi por completo marginal a la argumentación que allí desarrolla Hobbes ${ }^{8}$. Todo lo más, revela el más que explicable desconocimiento que el intelectual europeo de la época tenía de sociedades muy diferentes a la suya. Otras formas de humanidad que, sin embargo, apenas vislumbradas, comenzaban ya a golpear con fuerza la conciencia civilizada y para las que había que buscar un lugar en el discurso. Aunque, como en este caso, fuera un mal lugar.

\section{La problemática delimitación del ámbito político}

Lugar más decente fue el que les procuraron, mucho más tarde, los antropólogos evolucionistas, primero, y después sus críticos. Concretamente, los funcionalistas. A riesgo de simplificar con esas dos etiquetas convencionales la riqueza de posiciones y enfoques que una y otra encierran, podría decirse que los evolucionistas afrontaron el problema de la diversidad humana colocando sus pluriformes manifestaciones en una escala que era, ante todo, temporal. Los funcionalistas prescindieron de la escala, pero no de algunos supuestos fundamentales en que aquélla se cimentaba. Y uno de esos supuestos consistía, precisamente, en examinar la diversidad a través de la homogénea lente del Estado, que es nuestra más poderosa, cotidiana y absorbente realidad. De ello, como luego veremos, no se ven libres tampoco algunos antropólogos de nuestros días que parecen padecer de «estatofobia».

Muchas veces se han preguntado los antropólogos por qué no ha existido una antropología política claramente diferenciada hasta los años cuarenta de nuestro siglo (después aclararé las razones de esta fecha), mientras que, por el contrario, contamos con valiosísimas y vetustas aportaciones al campo de las creencias del ritual y del parentesco. De pasada, habría que decir que la pregunta está mal planteada: precisamente lo que sí han hecho bastantes antropólogos antes, en y después de los años cuarenta es negarse (implícita o ex-

"Véase Juan J. Ruiz-RIco, "Sobre una lectura posible del capitulo XIII de Leviathan", Anales de la Cátedra Francisco Suárez, núm. 14, pp. 161-185, especialmente p. 171. 
plícitamente) a seccionar las realidades socioculturales de modo arbitrario. El ejemplo más sobresaliente es, una vez más, Mauss y su noción de becho social total. Pero sigamos.

La respuesta, también convencional, a esa pregunta es que los grandes pioneros (y muy concretamente Lewis $\mathrm{H}$. Morgan) dividieron la historia del progreso humano en dos grandes etapas, significativamente caracterizadas por la presencia o ausencia del Estado. Morgan, ciertamente, habló de gobierno en un sentido tan laxo como para que pudiera aplicarse tanto a pueblos primitivos como a civilizados. Pero, para él, lo fundamental es la distinción entre dos formas de gobierno: societas y civitas (asignando la primera a los primitivos, o a las etapas anteriores a la civilización, y la segunda a los civilizados). La primera se caracteriza por las relaciones de consanguinidad entre los individuos (lo que después se llamaría sistema de parentesco); la segunda, por el surgimiento de la propiedad privada y por la presencia de un marco territorial: se trata de relaciones políticas ${ }^{9}$. Estamos ante la aparición del Estado. Dicho de otro modo, al equiparar lo político con lo estatal, Morgan consideró a la sociedad primitiva como carente de organización política. Parentesco y política venían, pues, a ser, en la perspectiva de Morgan, términos antitéticos, correspondientes a sociedades netamente diferenciadas en el pretérito y en el presente. De esa forma, el pensamiento evolucionista atribuía al mundo no occidental y a su propio pasado carácter social, pero le negaba carácter político. El parentesco (lo que Hobbes parece relegar a mero producto de la «natural lujuria», en el caso de las "gentes salvajes» ${ }^{10}$ ) venía a convertirse nada menos que en el gozne clave, en la gran etapa que, superando la promiscuidad inicial cercana a la naturaleza, conduciría, a su vez, al Estado.

Pero el establecimiento de esa dicotomía parentesco/política (o, lo que es lo mismo, primitivos/civilizados) apartaba, inevitablemente, a los antropólogos (dedicados entonces, y durante muchos años después, al estudio de los pueblos primitivos) del estudio de la política per $s e^{11}$.

Como vamos a ver enseguida, la rigidez de tal planteamiento se pierde

9 "La experiencia humana (...) ha desarrollado sólo dos planes de gobierno (...) La primera y más antigua fue una organización social, asentada sobre las gentes, fratrias y tribus. La segunda y posterior en el tiempo fue una organización politica, afirmada sobre territorio y propiedad. Bajo la primera se creaba una sociedad gentilicia, por medio de relaciones de gens a tribu. Estas relaciones eran puramente personales. Bajo la segunda se instituía una sociedad política, en la que el Gobierno actuaba sobre las personas a través de relaciones territoriales (...)". Lewis H. Morgan, La sociedad primitiva, Madrid, Ed. Ayuso, p. 126 (cursivas, del autor). Véanse también pp. 257 y ss., 1971 (e. o. 1877).

${ }^{10}$ Leviatán, ed. cit., p. 226.

"Como escribe M. G. Smith refiriéndose a Morgan: "Dado que esta teoría evolutiva se fundamentaba en su análisis de parentesco, el efecto inmediato de la obra de Morgan fue el centrar la atención en el estudio del parentesco y del matrimonio, a expensas de lo relativo al gobierno y a la política". Corporations and Society. The Social Anthropologogy of Collective Action, Chicago, Aldine, p. 74. 1975 (e. o. 1974). 
por obra y gracia de los antievolucionistas. Primero, en América, los continuadores de la obra de Franz Boas y, algo más tarde, la tendencia que encabezaba, en Inglaterra, Radcliffe-Brown, con sus ataques al evolucionismo morganiano, sientan las bases que conducen a nuestro presente.

Un discípulo de Boas, Robert H. Lowie, publica en 1920 un libro importante (Primitive Society) que, a veces implícita, a veces muy explícitamente, constituye un intento de refutar las tesis de Morgan. Las primeras frases de la Conclusión pueden darnos una idea del contenido de esta obra de Lowie:

«La sociedad primitiva presenta $(. .$.$) en realidad un carácter comple-$ tamente diferente del que la escuela de Morgan ha popularizado. En lugar de una monótona uniformidad, encontramos una diversidad matizada $(\ldots){ }^{12}$.

$Y$, en lo concerniente al estudio de las «instituciones políticas primitivas», Lowie destaca (como años más tarde hará Radcliffe-Brown en la obra que comentaré después) una notable carencia teórica. Es más, su propio acercamiento al problema no deja de ser tentativo y cauteloso:

«Yo no empleo de momento la palabra política más que por comodidad, y a fin de designar el conjunto de funciones legislativas, ejecutivas y judiciales; pero su empleo no indica ninguna solución anticipada del problema que estudiaremos después de haber enumerado los hechos» ${ }^{13}$.

Lo malo es que este punto de partida à la Montesquieu va a prejuzgar el análisis de esos hechos; por más que Lowie apunte enseguida, no exento de candor, que "Los tres poderes (...) se confunden a menudo». Pero lo que me importa resaltar es que el autor, al final de su análisis, subraya cómo la sociedad primitiva no carece de organización política, ya que, junto al parentesco, existen asociaciones voluntarias (tales como los clubs masculinos, las clases de edad o las organizaciones secretas); asociaciones independientes del parentesco que pueden llegar a revestir fácilmente un carácter político, si no lo presentaban desde el principio. El propio Lowie iba a desarrollar estas ideas años después (en The Origin of the State, 1927), al analizar el proceso de la génesis del Estado como producto debido, en gran medida, a los factores de desigualdad interna que crean asociaciones como las mencionadas.

Lowie, por tanto, no viene a cuestionar tanto la antítesis parentesco/política como a negar que la misma corresponda con exactitud a la dicotomía primitivo/civilizado. Con ello introduce definitivamente en el universo del

12 (Utilizo la versión francesa), Traité de sociologie primitive, París, Payot, página 397. 1936 (e. o. 1920).

Ibid.. J. 334 . 
discurso político (y no meramente social) a la humanidad entera ${ }^{14}$. Pero -y hay que subrayar esto- a costa de universalizar también la dicotomía entre dos esferas: la pública (asociaciones) y la privada (parentesco). Lo cual se acomoda perfectamente al estilo de vida y a la concepción del mundo burgueses; pero, por lo mismo, resulta más que problemática su universalización. Lowie traslada, además, la desigualdad en ciernes a la génesis misma de lo político (y, por ende, del Estado). Tenemos, pues, pacto (tímidamente oculto en las «asociaciones») y organización política sin necesidad de recurrir al otro vértice del triángulo: la guerra. $\mathrm{O}$, dicho de otro modo, Leviatán no crea la desigualdad; simplemente la consagra.

El planteamiento de los estructural-funcionalistas, que lidera RadcliffeBrown, es diferente en muchos aspectos al de Lowie. Entre otras cosas, creo, porque es más fiel a la interpretación convencional de la concepción hobbesiana de la política. Aparece expuesto con nitidez en el libro que, para muchos, marca el comienzo de una nueva etapa en el tratamiento antropológico de lo político, si no el nacimiento de la disciplina misma. No voy a detenerme aquí a discutir las razones por las cuales 1940 es un año importante en este orden de cosas. Sobre los factores coyunturales que hacen que en ese año se publiquen varios libros sobre política nativa africana se ha escrito bastante y no de buena calidad, en términos generales. No cabe dudar de la influencia de tales factores (necesidad del indirect rule, necesidad de «encontrar el jefe», el interlocutor válido, en pueblos donde las claves políticas no estaban en manos de líderes o instituciones reconocibles como políticas a ojos europeos). Pero vayamos a lo que trasciende las circunstancias del momento.

Pues bien, el libro más significativo en este orden de cosas es, sin lugar a dudas, African Political Systems ${ }^{15}$, libro compilado por Meyer Fortes y E. E. Evans-Pritchard y prologado por Radcliffe-Brown. Si nos atenemos a la declaración explícita de los compiladores, lo que ellos llaman «las teorías de los filósofos políticos» no les han aportado nada para comprender las sociedades estudiadas $\mathrm{y}$, por tanto, las consideran de escaso valor científico:

${ }_{14}$ En todo este trabajo estoy utilizando deliberadamente el término político con la suficiente amplitud para hacerlo equivalente nada menos que a to humano. Creo que hay que pensar como "ilustrados" (la Economia politica, no lo olvidemos, tuvo pretensiones de universalidad que luego se encargaron de disolver y fragmentar las disciplinas sociológicas surgidas en el siglo xIX); pero evitemos también los planteamientos dicotómicos - del tipo cultura/naturaleza, hombre/resto de las especies animales- y reconozcamos nuestra deuda con el evolucionismo (que nos impide dar el tremendo salto - aristotélico y hobbesiano- de los insectos sociales al hombre). Como escribe Robin Fox, "las hormigas pueden tener sociedades, pero las hormigas no tienen política. La política se presenta cuando los miembros pueden cambiar de lugar en una jerarquía como resultado de una competición. Por tanto, el hombre es más que social; es político, y es político porque es esa especie de primate terrestre y gregario", Encounter With Anthropology, Middlesex, Peregrine Books, p. 256, 1975 (e.o. 1973). Agradezco a Miguel Beltrán el que, con sus observaciones críticas, me haya hecho precisar este punto.

${ }_{15}$ African Political Systems, Edited by M. Fortes and E. E. Evans-Pritchard, Oxford University Press, 1970 (e. o. 1940). 
«La filosofía política se ha ocupado, principalmente, de cómo deberian vivir los hombres y de qué forma de gobierno deberian tener, en lugar de ocuparse de cuáles son sus hábitos e instituciones políticas» ${ }^{16}$.

Conviene apuntar que los compiladores de esta obra han recibido con posterioridad todo tipo de críticas por ese olímpico desdén respecto a siglos de reflexión acerca de lo político ${ }^{17}$. Pero al criticar esa suerte de adanismo, a! que tan dados son muchos antropólogos, tal vez no se haya reparado (con la excepción de David Easton) que hay algo peor que desdeñar la filosofía: hacer implícito uso de ella sin tan siquiera mencionarla. Eso es, precisamente, lo que ocurre en este caso. Porque de la concepción hobbesiana no están tan alejados estos antropólogos políticos. De ella les separan, obviamente, determinados postulados del funcionalismo empirista (tales como la convicción de que el origen de las instituciones no puede ser descubierto y que el estudio de las instituciones políticas debe ser inductivo). Pero les acercan otros más importantes.

Me referiré a estos últimos de la forma más breve posible. Para empezar - y no es el más importante-, el término gobierno, a diferencia del uso laxo que de él hacía Morgan, se restringe a aquellas sociedades que tienen un sistema político de tipo estatal (o, en la perífrasis de los compiladores, una state-like-structure, una «estructura semejante a la del Estado»). Pero no es de la tipología de los sistemas políticos de lo que quiero ocuparme aquí. Me importa la concepción que subyace a la taxonomía. Concepción que se pone más de relieve aún en el prólogo de Radcliffe-Brown. Allí se dice que para estudiar las instituciones políticas hay que asegurarse de que «lo político» define «una clase de fenómenos» ${ }^{18}$, aislable de otros rasgos del sistema social total:

«Al estudiar la organización política, tenemos que ocuparnos del mantenimiento o establecimiento del orden social, dentro de un marco territorial, mediante el ejercicio organizado de la autoridad coercitiva, a través del uso, o la posibilidad del uso, de la fuerza física» ${ }^{19}$.

O, más brevemente:

«La organización política es aquel aspecto de la organización total que se ocupa del control y regulación del uso de la fuerza física» ${ }^{20}$.

16 Ibid., p. 4 (cursivas, de los autores).

${ }_{17}$ La más certera es, probablemente, la de David Easton, op. cit. Véase también Georges Balandier, Anthropologie Politique, París, P.U.F., 1967.

${ }^{18} \mathrm{Op}$. cit., p. XII.

${ }^{19}$ Ibid., p. XIV (cursivas, mías).

20 Ibid., p. XXIII (cursivas, mías). 
Esto último, según Radcliffe-Brown, proporciona la definición más satisfactoria de esa clase especial de fenómenos y posibilita un estudio objetivo de las sociedades humanas con arreglo a los métodos de las ciencias naturales. No olvidemos que semejante pretensión animaba también la obra de Hobbes. ¿Qué ha ocurrido? Pues sencillamente que, pese a la distinción que se hace en la Introducción al libro mencionado entre sistemas políticos centralizados - estatales - y no estatales - acéfalos ( $\mathrm{y}$, más concretamente, el subtipo segmentario)-, a ambos se aplican las características definitorias de lo que se entiende por Estado: marco territorial definido y monopolio del uso legítimo de la violencia.

Nada de extraño tiene, planteadas así las cosas, que no se establezca ya una neta diferenciación (al modo de Morgan, e incluso de su crítico Lowie) entre parentesco y política. Lo que sí se hace es diferenciar la familia, en un sentido casi puramente biológico, del sistema de linajes unilineales y atribuir a estos últimos funciones políticas en las denominadas sociedades segmentarias. ¿Por qué politicas? Porque los linajes son internamente solidarios y externamente hostiles (al menos, en potencia) frente a otros grupos de su misma estructura. Minúsculos «estados», podríamos pensar. Pero la cosa es bastante más complicada. Porque, como estudiaría Evans-Pritchard en su primera monografía sobre los nuer (publicada ese mismo año de 1940), lo que caracteriza a una sociedad segmentaria como ésa es su relatividad estructural ${ }^{21}$. En virtud de este principio, los grupos ( $\mathrm{y}$, en definitiva, el territorio mismo que ocupan) que a un determinado nivel o en unas determinadas circunstancias aparecen enfrentados, en otros niveles o en otras circunstancias son solidarios. Dicho de otro modo: los grupos sólo existen - en el plano del pensamiento y en el plano de la realidad-en relación con otros grupos.

Pero este magnífico hallazgo teórico de Evans-Pritchard queda casi oculto por el momento. Predomina en la época la idea de que, por minúscula que sea, la comunidad política se caracteriza por la supresión de la lucha interna (la «guerra civil» hobbesiana) y por la hostilidad de fronteras afuera. Sin embargo, el propio Radcliffe-Brown se ve en apuros cuando trata de distinguir entre guerra y feud (las interminables vendettas que caracterizan a las sociedades segmentarias a raíz de homicidios, robos, adulterios, etc., y que ponen de relieve, precisamente, la relatividad estructural). Lo que hace es remitir estas últimas al terreno de lo que puede ser resuelto mediante arbitraje: en suma, a la decisión de alguna autoridad por encima de las partes ${ }^{22}$. El problema es que, como muestra Evans-Pritchard en su estudio de los nuer, un árbitro de este tipo (como es el «hombre de la piel de leopardo») sólo puede resolver aquellas disputas que a las partes contendientes interesa que se resuelvan. Podríamos decir, por tanto, que en esas sociedades el pacto, el con-

"The Nuer: A Description of the Modes of Livehood and Political Institutions of a Nilotic People, O.U.P., 1940.

${ }_{22}$ Op. cit., p. XX. 
trato social, se está celebrando tantas veces cuantas está siendo revocado para iniciar de nuevo el proceso.

El trasfondo del orden político vuelve a ser de nuevo - y esta vez por obra de los estructural-funcionalistas - la guerra. No deja de ser interesante que los antropólogos hayan prestado tan poca atención (hasta hace relativamente poco tiempo) al estudio de los fenómenos bélicos. El propio RadcliffeBrown lo ponía de relieve en 1940 . Y afirmaba, además, con una rotundidad que, más que a Hobbes, recuerda cierta frase del Manifiesto Comunista:

«al menos la mitad de la historia del desarrollo político es, de una u otra forma, una historia de guerras» ${ }^{23}$.

Probablemente, esa falta de interés por lo bélico de tiempos atrás se deba al correspondiente poco interés por lo político. Pero hay también otras razones. Un moderno estudioso de la antropología de la guerra, Keith Otterbein, da tres razones para explicar el porqué de ese desinterés ${ }^{24}$ :

a) Una razón fáctica: los pueblos que estudiaron los antropólogos (incluso desde el siglo xxI) habían cesado de guerrear, sometidos como estaban a la pax britannica o a otras impuestas por las potencias coloniales.

b) Una razón ideológica: muchos de los primeros antropólogos eran decididos enemigos de la guerra (Tylor era cuáquero, Boas era profundamente antibelicista).

c) Una razón metodológica: los primeros antropólogos no supieron apreciar el importante papel que la guerra juega en las sociedades primitivas, atentos como estaban, sobre todo, a la mitología y al folklore.

Habría que añadir que del poco o nulo interés por la guerra en antropología, hace ya muchos años, se ha pasado a una auténtica obsesión por el tema. Pero hay muchas y divergentes interpretaciones antropológicas acerca de la guerra. Pocos antropólogos estarían dispuestos a ver hoy en la guerra (fenómeno colectivo y no pelea entre dos individuos) una mera continuación de instintos agresivos. De las teorías de Lorenz al respecto se dice - lo recalca el propio Otterbein- que han despertado auténticos instintos de agresividad en muchos antropólogos contemporáneos. No obstante, hay quienes, concibiendo la guerra como un fenómeno universal (propio de la especie humana, pero transcultural), ven en ella un mecanismo fundamental para la adaptación del hombre a su medio ambiente. Darwinismo subyacente éste

${ }^{23}$ Ibid., p. XIX.

24 "The Anthropology of War", en J. J. Honigman (ed.), Handbook of Social and Cultural Anthropology, Chicago, Rand McNally \& Company, pp. 923-958, 1973. El artículo ofrece un excelente resumen de las diferentes perspectivas antropológicas sobre los fenómenos bélicos; lo utilizo en los párrafos que siguen, salvo que indique otra cosa. 
donde parecen coincidir neoevolucionistas y propugnadores del neofuncionalismo ecológico ${ }^{25}$. Otros antropólogos, en cambio, ven en la guerra, ante todo, el producto de una invención humana relativamente tardía (cuando de la evolución de la especie se trata). Los hallazgos más recientes de la paleontología parece que vienen a confirmar esta segunda teoría: los artefactos de piedra que se encuentran junto a los restos fósiles de nuestros probables antepasados homínidos, más que armas, parecen destinados a macerar y a hacer deglutible la carne a un animal escasamente dotado para ser carnívoro ${ }^{26}$. Por otra parte, revisando la bibliografía que al respecto existe sobre el Pleistoceno, Marilyn K. Roper afirma que, aunque parece que hay pruebas de muertes intrahumanas esporádicas, los datos conocidos no son suficientes para documentar la presencia de la guerra en tan prolongado período de tiempo ${ }^{27}$. Probablemente, cabría agregar, nunca llegaremos a saber si el trasfondo de la política de nuestros antepasados - los auténticos primitivos-- fue también la guerra; pero los que por analogía, no exenta de errores, llamamos primitivos contemporáneos la conocen y la practican.

Con todo, conviene tener en cuenta un par de cosas. En primer lugar, algo que ya apuntara Boas hace más de cincuenta años: que el concepto de guerra es eso, un concepto y no una unidad empírica, y los fenómenos agrupados en él pueden ser enormemente diversos, en significado y contenido, de una sociedad a otra ${ }^{28}$. Y, en segundo lugar, que la dificultad de conceptualizar lo que llamamos guerra en sociedades muy diferentes de la nuestra estriba, además, en que en ellas es francamente difícil deslindar lo bélico de otras esferas de acción no bélicas. Las fronteras entre la guerra y la paz son en ellas mucho más lábiles y fluctuantes que en el llamado mundo civilizado. Ilustraré lo que acabo de afirmar con la ayuda de la etnografía y de la filología.

Para lo primero contamos con ese mundo (prácticamente desconocido hasta la segunda guerra mundial) que es el interior de Nueva Guinea, y en el que bastantes antropólogos han creído encontrar una perfecta muestra de lo que pudo haber sido la auténtica sociedad primitiva. Sea como fuere (no voy a valorar esta forma de ver las cosas ${ }^{29}$ ), los grupos humanos de esa zona se caracterizan por una intensa belicosidad. Belicosidad contra la que intentó

${ }_{25}$ Puede leerse una acertada crítica de este último en C. R. Hallpike, "Functionalist interpretation of primitive warfare", Man, N. S., vol. 8 , núm. 3, pp. 450470, 1973.

${ }^{26}$ Véase, por ejemplo, Robin Fox, "The Evolution of Mind: an Anthropological Approach", Journal of Anthropological Research, vol. 35, núm. 2, pp. 138-176, 1979.

27 Citado por K. OtTerbern, op. cit.

28 "The Aims of Anthropological Research", incluido en Race, Language and Culture, New York, The Free Press, pp. 243-259, 1966 (e. o. 1940).

${ }^{29}$ Se dispone ya hoy de pruebas históricas más que suficientes para refutar esa perspectiva de antropólogos y no antropólogos. De ello dan cuenta obras como la de Eric R. Wolf, Europe and the People without History, Los Angeles, Univ. of California Press, 1983, o la de Roger M. KeEsing, Cultural Anthropology. A Contemporary Perspective, New York, Holt, Rinehart and Winston, 2nd. ed., 1981 (e. 0.1976$)$. 
todo la administración fideicomisaria australiana y apenas consiguió nada. Tampoco lo han conseguido las nuevas autoridades de Papúa-Nueva Guinea, independiente a todos los efectos a partir de $1975^{30}$. Pues bien, lo que caracteriza a esas poblaciones humanas es una continua oscilación entre la guerra y el intercambio matrimonial y comercial, entre el canibalismo o la mutilación vejatoria del enemigo muerto y la difícil alianza, entre la agresión y la fiesta. El territorio mismo que les sirve de asentamiento físico carece de fronteras permanentes y estables ${ }^{31}$.

Y si preferimos movernos en el tiempo en lugar de en el espacio, la moderna filología nos proporciona algunas claves. Pensemos que bostilidad y hospitalidad tienen una y la misma raíz etimológica. Sin embargo, el término bostis, dice Emile Benveniste, no tiene en el latín más antiguo el significado de enemistad que adquiere posteriormente. Es, por el contrario, el extranjero (el xénos homérico) con el que se mantiene una relación de reciprocidad: bostire equivale a reciprocar. Pero añade Benveniste:

«Cuando la antigua sociedad deviene nación, las relaciones de hombre a hombre, de clan a clan, quedan abolidas; sólo subsiste la distinción de lo que es interior o exterior a la ciuitas. Por un cambio del que no conocemos las condiciones precisas, la palabra bostis toma una acepción "hostil" y en adelante no se aplica más que al enemigo» ${ }^{32}$.

¿No podría invertirse, por tanto, el argumento hobbesiano y pensar que es el Estado (cualquier Estado, o, en este caso, el romano) el que crea la auténtica y fatídica guerra? Porque lo anterior -o lo ajeno- al Estado, por violento y destructor que sea, es, al propio tiempo, lúdicro y unificador potlatch. No deja de ser interesante que fuera el propio Radcliffe-Brown quien nos recordara que el pólemos pater pánton heraclitiano no significaba sólo guerra, sino también asociación o integración de contrarios o de opuestos $^{33}$.

Aunque, tal vez, el problema no sea tanto de Hobbes como de aquellos a quienes Nicolás Ramiro Rico llamaba «pseudohobbesianos mistificantes» ${ }^{34}$. A esta no infrecuente especie pertenecen tanto admiradores como denostadores del filósofo inglés. Me temo que Pierre Clastres ande, cuando menos, bastante cerca de la especie. Incurre, en todo caso, a mi modo de ver, en el

30 Véase Paula Brow, "New Guinea: Ecology, Society and Culture", Annual Review of Anthropology, vol. 7, pp. 273-291, 1978.

" Véase C. R. HALlPIKe, op. cit.

32 Op. cit., pp. 92-96 (cita literal, p. 95).

${ }^{33}$ El método de la antropología social, Barcelona, Anagrama, p. 140, 1975 (edición original 1958).

${ }^{34}$ El animal ladino $y$ otros estudios politicos, Madrid, Alianza Editorial, p. 45, 1980. La expresión aparece en el contexto de una reflexión más amplia sobre agresividad, violencia y guerra. Sobre esta última, véase también otro de los trabajos incluidos en el mismo libro, "Guerra y técnica". 
error de la excesiva literalidad de la lectura hobbesiana. También Clastres - pese a que lo niegue- llega a ver la realidad otra a través de la realidad próxima, la estatal. Para él hay, fundamental y exclusivamente, dos tipos de sociedades: la que ha caído ya en las garras de Leviatán y la que lucha con todas sus fuerzas para no ser presa de las fauces del monstruo. Esto es, la «sociedad contra el Estado. Ambas son, bien es verdad, sociedades políticas; pero mientras la primera se cimenta sobre la desigualdad, la segunda la niega y consagra el más puro y utópico de los igualitarismos. Sencillamente, porque el jefe en ellas carece de poder coactivo; o, dicho de otro modo, lo político y lo social se funden en el Uno absoluto" ${ }^{35}$.

Lo malo es que la prosa de Clastres, con frecuencia fascinante, oculta algo elemental: que es realmente difícil rebatir afirmaciones tan rotundas como ésas. ¿A qué sociedades primitivas o contra el Estado se refiere? Sus ejemplos etnográficos (cuando no son meras generalizaciones transculturales) sirven más para ilustrar malabarismos verbales que para dar solidez empírica a la argumentación. Los pueblos de la Suramérica indígena que él conoció carecen, sin duda, de un jefe equiparable a Cromwell, al Lord Protector; pero ¿puede uno darse por satisfecho si el elemento coactivo no aparece donde el hombre de la calle europeo esperaría encontrarlo? Para Clastres, el problema de la definición de lo político se resuelve fácilmente. Político es o bien lo que tiene que ver con el Estado (poder coactivo) o bien lo que niega al Estado (poder no coactivo: por ejemplo, el discurso -lanzado para no ser oído- del jefe del poblado guaraní). Pero ¿es que en el Estado sólo hay poder coactivo y sólo poder no coactivo fuera del Estado? ¿Es que lo político se reduce al poder o a la dominación? ${ }^{36}$.

Sin embargo, Clastres plantea el triángulo guerra, pacto y orden político con tal nitidez que merece que le prestemos atención. Lo plantea en el contexto de una discusión en torno a la guerra primitiva ${ }^{37}$. En esa discusión, Clastres opone, fundamentalmente, el discurso hobbesiano ( «la guerra de todos contra todos») al discurso lévi-straussiano («los intercambios económicos - dice Lévi-Strauss- representan guerras potenciales resueltas pacíficamente, y las guerras son resultados de transacciones desafortunadas»). Pero esto último - ya lo he apuntado y volveré a ello después - no es sino un desarrollo fecundo, pero parcial, del «Ensayo sobre el don» de Mauss (al que ni siquiera alude Clastres). Pues bien, lo que viene a decir Clastres es que mientras que Hobbes no ve sino guerra en la vida primitiva (y el Estado se hace necesario

${ }^{35}$ Acerca de todo esto, véase su libro más popular: La sociedad contra el Estado, Barcelona, Monte Avila Editores, 1978 (e. o. 1974).

36 Una crítica a estos planteamientos de Clastres puede leerse en Jean-William LAPIERRE, Vivre sans Etat? Essay sur le pouvoir politique et l'innovation sociale, París, pp. 323 y ss., 1977.

37 "Arqueología de la violencia: la guerra en las sociedades primitivas", en Investigaciones en Antropología política, Barcelona, Gedisa, pp. 181-216, 1981 (edición original 1980). 
para favorecer el comercio), Lévi-Strauss, por el contrario, relega la guerra al status de comercio frustrado. Cada uno acierta, según Clastres, en lo que el otro se equivoca: Hobbes, porque no pudo saber que el comercio juega un papel importante en la vida de quienes él llamó salvajes (¿hará falta insistir en que el capítulo XIII no es el todo Hobbes?); Lévi-Strauss yerra, por su parte, al hacer depender la guerra del intercambio. Solución de Clastres: la guerra es el arma política por excelencia para mantener la independencia del grupo local (el pequeño poblado indígena). Y para poder guerrear hay que tener aliados y, claro está, enemigos. Bien entendido que quienes hoy son nuestros aliados, mañana pueden ser nuestros enemigos, y, por supuesto, a la inversa. Pero el poblado mantiene siempre su identidad. Conclusión: «El Estado está contra la guerra» de Hobbes es afirmación tan cierta como la que inversamente nos enseñan los primitivos, que «la guerra está contra el Estado».

Tal vez resulte cruel argumentar que tras la máscara de cada poblado autárquico de Clastres se oculta un minúsculo Leviatán, que se ve impelido a guerrear permanentemente con los de fuera para impedir la división interna. Pero no es difícil encontrar una sorprendente semejanza entre lo que constituye el eje de la política para Clastres (la diferenciación necesaria entre hostiles y aliados) y la conocida definición de política del, en otro tiempo, hitleriano Carl Schmidt:

«La distinción específica de lo político, en la cual pueden englobarse los actos y los móviles políticos, es la discriminación entre amigo y enemigo» ${ }^{38}$.

Distinción quién sabe si universal, como pretendía Schmidt, pero, en todo caso, de problemática especificidad.

\section{De las cosas a las representaciones}

Creo que dos autores tan disímiles como Radcliffe-Brown y Clastres, al intentar prolongar la reflexión política más allá del Estado, incurren en errores de perspectiva semejantes. Tal vez, porque ninguno de ellos ha sabido apreciar que lo político constituye no tanto -o no sólo- un orden de fenómenos (de cosas, en un sentido estrechamente durkeimiano) cuanto un orden de representaciones (en un sentido ampliamente durkeimiano y, sobre todo, maussiano).

El propio Estado hobbesiano se configura como representación, como persona colectiva, y el concepto mismo de persona ya es dramatúrgico, como

${ }^{38}$ Citado por J.-W. LAPIERRE, op. cit., p. 266. 
recordara Hobbes mismo ${ }^{39}$. Más aún, pensemos que los rituales de investidura de las sociedades tribales y de las sociedades burocratizadas convierten a simples individuos - por más ineptos que nos parezcan- en representantes de la colectividad y, como tales, dotados de autoridad y dignidad ${ }^{40}$. En las sociedades tribales, las diversas fases de tales ritos acentúan o exageran, teatralizan en una palabra, como ha mostrado Victor W. Turner, la poquedad, la miseria del elegido. Los informantes ndembu decían a Turner: "Un jefe es exactamente igual que un esclavo la noche anterior a su nombramiento» ${ }^{41}$.

Por otra parte, cualquier colectividad (sea la que corporiza el Estadonación, sea la del poblado amazónico o neoguineano) necesita, además, representarse al otro como amigo o como enemigo antes de poder aliarse con él o luchar contra él. Vistas así las cosas, la distinción que C. Schmidt concibe como primaria y universal no puede considerarse, como mucho, más que como secundaria o derivada. Un evolucionista como E. B. Tylor planteó, hace casi cien años, el problema de la exogamia en términos que tienen aún hoy plena vigencia:

«Una y otra vez en la historia del mundo las tribus salvajes deben haber puesto ante sus mentes esta sencilla y práctica alternativa: casarse con los de fuera o ser exterminados por los de fuera» ${ }^{42}$.

Lo que no pudo saber Tylor es que tal dilema no queda resuelto de una vez y por todas. Hostilidad y alianza se funden en la repetida frase que han recogido los antropólogos de nuestra época: «nos casamos con aquellos con quienes luchamos». Lo que ocurre es que las sociedades avanzadas, industrializadas, son mucho más crueles: llegado el caso, exterminan a los de fuera sin casarse con ellos. No sólo eso, sino que, además, crean lo que C. Schmidt llamaba el «enemigo interior» (el disidente) y acaban por exterminarlo también. Pero no está de más recordar que el holocausto judío de la Alemania nazi tenía tras de sí una larga historia de representaciones colectivas acerca de la perfidia semita.

Creo que es el momento de atar algunos cabos que han ido quedando sueltos y de bosquejar otros que pueden completar las líneas generales del intrincado desarrollo de la antropología política. La antropología evolucionista

${ }^{39}$ Leviatán, ed. cit., pp. 255 y ss. Carlos Moya lo resalta en la introducción a esta edición, p. 103.

40 Véase el magnífico trabajo de Meyer Fortes al respecto: "Ritual and Office in Tribal Society", en Max Gluckman (ed.), Essays on the Ritual of Social Relations, Manchester University Press, pp. 53-88, 1966 (e.o. 1962).

${ }^{41}$ The Ritual Process. Structure and Anti-Structure, Londres, Routledge and Kegan Paul, p. 101, 1969.

42 "On a Method of Investigating the Development of Institutions; Applied to Laws of Marriage and Descent" (1889). Reimpreso en Nelson Graburn, Readings in Kinship and Social Structure, New York, Harper \& Row, pp. 19-30 (cita literal, p. 29), 1971. 
-especialmente con Morgan- concibió el desarrollo de la humanidad como el paso de las relaciones personales — de parentesco- a las relaciones políticas. Los críticos del evolucionismo (primero los boasianos, luego los funcionalistas) universalizaron el concepto de política. Pero en la distinción entre sistemas políticos estatales y no estatales late aún el viejo esquema evolucionista, sólo que privado de sus dimensiones temporales o secuenciales. Se había dado, con todo, un paso decisivo - y, probablemente, imprevisto- en la concepción antropológica de lo político, que superaba a la crítica de Lowie: el parentesco se concibe, a partir de entonces, no ya como algo que está junto a la política, sino como algo que puede ocupar su lugar, actuar en su nombre. En suma, representarla, simbolizarla. Los discípulos y colaboradores de Max Gluckman profundizarían en esa dirección. Unos, como M. G. Marwick, verían el conflicto inherente a muchas sociedades de tecnología elemental, expresado a través de las mutuas acusaciones de hechicería entre las partes contendientes ${ }^{43}$. Otros, como Turner, analizarían cómo (en una sociedad con un sistema de filiación matrilineal y un tipo de residencia patrilocal - los ndembu de la actual Zambia-) los rituales colectivos, lejos de expresar o reflejar la unidad social, la hacen pasajeramente posible, luchando, de ese modo, contra el siempre previsible cisma que alientan las contradicciones internas ${ }^{44}$. Los nuevos enfoques, al llevar la dimensión analítica del conflicto a las esferas antes pacíficas del ritual y del parentesco, pugnaban con las fronteras convencionales entre lo político y otros ámbitos de acción. Fronteras tan queridas, por otra parte, por científicos de la política como David Easton ${ }^{45}$. Pero esos nuevos planteamientos ya estaban preanunciados en el análisis frazeriano de la monarquía divina, o en el atisbo de Malinowski (cuando vio en el mito una constitución no escrita), o en los estudios - hoy recuperados después de un largo tiempo de injustificable olvido- de Arthur M. Hocart.

En este contexto hay que situar también una obra muy importante de Edmund R. Leach ${ }^{46}$. Leach se rebela contra el postulado estructural-funcionalista de que los sistemas políticos son realidades naturales, sistemas en equilibrio estable $y$, en definitiva, una clase real de fenómenos. $Y$ al hacerlo recupera, significativamente, la dimensión perdida — la temporal-. Leach, en

${ }^{43}$ Sorcery in its Social Setting. A Study of the Nothern Rodhesian Cêwa, Manchester University Press, 1965.

${ }^{4}$ Schism and continuity in an African Society. A study of Ndembu village life, Manchester University Press, 1972 (e. o. 1957).

"Fue probablemente Abner Cohen el primer antropólogo que supo dar una respuesta al desafio que contenía el artículo mencionado de D. Easton y, también, quien más ha insistido en estos últimos años en destacar la dimensión simbólica en los análisis antropológico-políticos. Véanse sus artículos "Political Anthropology: The Analysis of the Symbolism of Power Relations", Man, N. S., vol. IV, número 2, 1969, pp. 215-255, y "Political Symbolism". Annual Review of Anthropology, vol. 8, pp. 87-113, 1979.

${ }_{46}$ Political Systems of Highland Burma. A Study of Kachin Social Structure. London, The Atholone Press, 1970 (e. o. 1954). 
su estudio sobre los kachin de las colinas birmanas, pone de nuevo a Morgan sobre el tapete, pero para eliminar de su esquema la ingenua rotundidad que lo caracterizaba. Los kachin no superan de una vez por todas el umbral del Estado, pero tampoco logran una victoria definitiva contra aquél. Antes al contrario, las tribus kachin oscilan, a través del tiempo, entre dos polos, sin caer por completo en ninguno de los dos: el extremo anárquico (gumlao) y el extremo proclive a la tiranía (gumsa). Bien entendido que gumsa y gumlao son -tanto desde la perspectiva del antropólogo como de la gente que él estudia- tipos ideales, categorías mentales expresadas verbalmente, imposibilidades fácticas, negadas siempre cuando están a punto de realizarse plenamente. Va de suyo que gumsa y gumlao carecen de entidad objetiva absoluta; existen, sí, pero más que nada en la representación simbólica que de ellos se hacen los kachin, y sólo puede concebirse uno en relación con su opuesto.

$\mathrm{El}$ análisis de Leach ha sido sometido a fuertes críticas. Pero es interesante resaltar que las más acerbas (provenientes de antropólogos marxistas), más que rebatir totalmente las conclusiones de Leach, lo que hacen es relativizarlas ${ }^{47}$. Con lo cual la crítica al realismo o esencialismo radcliffe-browniano queda aún más patente. Parece que hay que buscar, por tanto, otros cauces para la antropología política que los que se marcaron en 1940.

\section{El don politico de Marcel Mauss}

Ese dotar el análisis de dimensión simbólica presta, sin duda, una mayor universalidad al discurso político. Lo hace inexorablemente humano. Pero ¿no lo aleja demasiado de las grandes y vetustas reflexiones acerca de lo político? No, siempre que, además, añadamos otras dos cosas: una lectura menos mistificante y menos literal de Hobbes y una vuelta a los clásicos. Pues bien, en el olvidado - por los antropólogos de la política- «Ensayo sobre el don» de Mauss parece que se apunta a una y a otra. Pero también del famoso «Ensayo» han hecho los antropólogos lecturas diversas. Voy a sintetizarlas en las tres siguientes.

Una primera es la lectura economicista. No voy a detenerme mucho en ella. Es la más frecuente y la más persistente. Aparece en libros introductorios a antropología y, claro está, en publicaciones más especializadas sobre antropología económica. Supone colocar el «Ensayo» en el inicio de las preocupaciones de los antropólogos por las formas de intercambio de los pueblos no occidentales. No obstante, con ser la lectura aparentemente más obvia (recordemos que el subtítulo del «Ensayo» reza así: «Forma y razón del intercambio en las sociedades arcaicas»), no es la menos problemática.

47 Véanse, por ejemplo, Jonatham FrIEDMan, "Tribus, estados y transformaciones", en Análisis marxistas y antropologia social, textos compilados y prologados por Maurice Bloch, Barcelona, Anagrama, 1977 (e. o. 1975) y E. R. WoLf, op. cit., páginas 344-346. 
Entre otras muchas razones, porque todo el trabajo constituye, de modo deliberado, un intento por situar el intercambio fuera o más allá de la esfera puramente económica. Al margen, en todo caso, de lo que la economía liberal o el pensamiento marxista entienden por económico (o, para ser más exactos, de lo que los durkeimianos concibieron por marxismo).

Una segunda lectura, mucho más fecunda, es la que realiza Lévi-Strauss. Le sirve para fundamentar nada menos que toda la arquitectura de Las estructuras elementales del parentesco. Conviene tener en cuenta que, en el «Ensayo», Mauss recalcaba el carácter total de las prestaciones, de los intercambios, en las sociedades arcaicas y primitivas e insistía en que, en ellas, no sólo los objetos, sino los individuos mismos - y concretamente las mujeres- circulaban entre los grupos sociales. Eran, pues, los grupos los que se daban unos a otros a través de sus propios miembros. Tal observación no pasó inadvertida para todo un grupo de antropólogos holandeses (pertenecientes a la denominada Escuela de Leiden), quienes en los años treinta estudiaron, en algunas sociedades indonesias, un sistema de intercambio matrimonial que suponía, precisamente, la circulación de mujeres a través de grupos de filiación unilineal (al que denominaron «connubio circular»). Pero lo que para la Escuela de Leiden había sido nada menos - pero, también, nada másque un valioso instrumento heurístico, Lévi-Strauss lo elevó a principio explicativo - universalmente válido- de la génesis estructural de los sistemas de parentesco ${ }^{48}$. Más aún, lo que Lévi-Strauss reprocha a tan colosal fuente de inspiración como es el «Ensayo» es que Mauss, habiendo vislumbrado las inmensas posibilidades analíticas del intercambio como generador subyacente de las operaciones empíricas de dar, recibir y devolver, se quedara tan sólo en la superficie del fenómeno. Peor aún: que Mauss tratara de dar el paso de la descripción etnográfica a la explicación sociológica, recurriendo a la racionalización indígena (neozelandesa, en este caso) del fenómeno: la fuerza mística, el bau de las cosas que obliga a los dones a circular, a ser entregados y a ser devueltos ${ }^{49}$. Fuerza espiritual que Mauss cree adivinar, si bien en grados muy diversos, tras realidades sociales tan distintas y distantes como el potlatch de la Norteamérica indígena, el kula melanesio, los sistemas jurídicos de nuestro pasado indoeuropeo e incluso ciertos aspectos de la legislación de las sociedades modernas (como la regulación de la propiedad intelectual).

Pues bien, es la lectura lévi-straussiana (el intercambio como gozne entre la naturaleza y la cultura) la que puede darnos la clave de una tercera lectura que es la que aquí me interesa: la lectura política. Pero debo advertir inmediatamente que no es el tipo de lectura que hace Lévi-Strauss. Lévi-Strauss

4 Véase Rodney Nempham, Structure and Sentiment. A Test Case in Social Anthropology, Chicago, The University of Chicago Press, p. 7., 1969 (e.o. 1962).

49 "Introduction a l'oeuvre de Marcel Mauss", Sociologie et Anthropologie, citado, pp. XXXVIII-XXXIX. 
(diré utilizando casi sus propias palabras contra Mauss) la vislumbra, pero decide quedarse en el umbral. Porque, para Lévi-Strauss, los intercambios (el contrato social maussiano, como bien ha visto Sahlins) se apoyan en algo tan alejado de la consciencia como es el principio de reciprocidad, tal como él lo entiende, enraizado, a su vez, en el discutido y discutible esprit bumain.

Sin duda, a cada gran concepción de la política y de la sociedad subyace, cuando menos, una concepción de la naturaleza — término polisémico si los hay- Pero la de Lévi-Strauss (que reduce en último extremo el polémico esprit humain a los componentes físico-químicos del cerebro) poco tiene que ver tanto con la noción de pbysis de los griegos como con las leyes de la naturaleza hobbesianas. Se sitúa mucho más allá de la pólis y, por supuesto, a astronómica distancia del contrato social. Otras alusiones esporádicas de Lévi-Strauss a la política de las sociedades primitivas (como la absoluta unidad, la resistencia al cambio o la inexistencia de conflictos internos) constituyen, probablemente, la fuente de inspiración de Clastres, y sus supuestos han sido ampliamente cuestionados por antropólogos como Balandier ${ }^{50}$.

Sahlins sí hace una lectura política del texto maussiano, como he apuntado más de una vez. Lectura que no excluye - no puede excluir- las anteriores (la económica y la del parentesco), sino que las integra, ya que cuestiona, una vez más, la artificiosidad de esas fronteras. La originalidad de Sahlins estriba en hacer una doble y paralela lectura del Leviatán y del «Ensayo», que viene a poner de relieve cómo ambos son complementarios. Analizada por Sahlins, la obra de Hobbes se nos muestra sorprendentemente actual. Es más, argumenta Sahlins, la cuarta de las «leyes de la naturaleza», según Hobbes (la Gratitud), que depende de una donación previa, no es sino el precedente remoto del don maussiano, de la reciprocidad, en suma ${ }^{51}$. Mauss lo que hace es ampliar el espacio humano que media entre naturaleza y civitas al tratar de comprender aquellas otras sociedades que, sin necesidad de Leviatán, han sabido: "oponerse sin masacrarse y darse sin sacrificarse los unos a los otros» ${ }^{52}$. Y, poco antes, citando a Malinowski, Mauss escribe:

«Los hombres de Dobu - dice un isleño de las Trobriand- no son buenos con nosotros; son crueles; son caníbales; cuando llegamos a Dobu los tememos. Podrían matarnos. Pero he aquí que yo escupo la raíz de jengibre y su espíritu cambia. Deponen sus lanzas y nos reciben bien» ${ }^{53}$.

«Nada expresa mejor --comenta Mauss - esta inestabilidad entre la fiesta y la guerra.» Esto tiene, quizá, un remoto parecido con la inversión que Michael Foucault hace de la célebre fórmula de Clausewitz, cuando afirma

so Anthropo-logiques, París, P.U.F., pp. 180 y ss., 1974.

"Op. cit., p. 178.

${ }_{52}$ Sociologie et anthropologie, cit., p. 278.

53 Ibid. 
que «la política es la guerra continuada con otros medios» ${ }^{54}$. Pero el espíritu es diferente, porque son otra guerra y otra política las de Mauss.

No obstante, es de lamentar que Sahlins no se haya percatado totalmente de cómo Mauss amplía, de modo revolucionario, el universo del discurso político. Porque Mauss, a mi entender, no sólo recupera el auténtico discurso hobbesiano (que no es tanto «la guerra de todos contra todos», sino - como nos hace ver Sahlins- «la guerra contra la guerra»), sino que va más allá. Atribuye a otras formas de humanidad (las que él engloba en ese término un tanto vago de sociedades segmentarias) el mismo entendimiento prudente de la situación», la misma phronesis que los clásicos limitaron al reducto de la pólis. Porque nos enseña, también, que podemos vislumbrar la phronesis que se oculta tras el insospechado ropaje simbólico del salivazo, de las lanzas depuestas y de la fiesta.

Entendido así el planteamiento de Mauss, nada tiene de extraño el que haya tratado de buscar en una noción mística - pero consciente- como la de bau el fundamento del intercambio, del contrato social. Mauss se equivocó, probablemente (como han señalado otros antropólogos, en contra de lo que opina Lévi-Strauss ${ }^{55}$ ), en la interpretación religiosa que dio de aquella noción indígena. Nada tiene de extraño que así fuera, porque no tenía un conocimiento directo de los temas de que trataba en sus obras. Sin embargo, no anduvo desacertado al situar el fundamento de la convivencia política en el reino de la consciencia. $Y$ pienso que se adecua mejor al talante de Mauss la «norma de reciprocidad», tal como la formuló Alvin W. Gouldner, que el «principio de reciprocidad» lévi-straussiano. Para Gouldner, la reciprocidad es, ante todo, una norma moral que sirve no sólo para estabilizar los sistemas sociales (al modo como la entendió el funcionalismo), sino que constituye, también, un importante «mecanismo iniciador» de sistemas sociales, sea a escala interindividual o a escala internacional ${ }^{56}$.

Al fino olfato de Sahlins parece habérsele escapado estas reveladoras palabras con las que Mauss concluye el «Ensayo sobre el don»:

«Estudios de este género permiten (...) entrever, medir, sopesar los diversos móviles estéticos, morales, religiosos, económicos, los diversos factores materiales y demográficos cuyo conjunto fundamenta la sociedad y constituye la vida común, y cuya dirección consciente es el arte supremo de la Política en el sentido socrático del término» ${ }^{57}$.

No creo que sea necesario resaltar en exceso tres palabras de este párrafo: consciente, arte y socrático.

${ }^{54}$ Microfísica del poder, Madrid, Las Ediciones de La Piqueta, p. 135, 1978.

$5 s$ Véase Sahlins, op. cit., pp. 153-157.

so "La norma de reciprocidad: formulación preliminar", en La sociología actual: renovación y crítica, Alianza Editorial, pp. 214-244, 1979 (e.o. 1973).

st Sociologie et anthropologie, cit., p. 279. 


\section{Conclusión}

En el libro primero de La Politica, Aristóteles niega carácter humano al enemigo de la «sociedad ciudadana»; tal tipo es:

«o bien un ser inferior o más que un hombre (...). Al mismo tiempo, semejante individuo es, por naturaleza, un apasionado de la guerra $(\ldots) \gg{ }^{58}$.

El logos de Occidente (el de Aristóteles, el de Hobbes) parece oponer siempre la organización política (cultura) a la guerra (naturaleza o mera animalidad). La antropología — que procede, no lo olvidemos, del mismo logosha tenido que realizar el esfuerzo titánico de comprender otras formas de humanidad (ni animales, ni dioses) que habían logrado una difícil e inestable síntesis entre aquellos extremos. Además, gracias a Mauss, la antropología política - por insospechados y tortuosos vericuetos- puede vanagloriarse de haber recuperado la dimensión de los clásicos, sin perder por ello el realismo de los modernos.

Hace ya muchos años, Arthur M. Hocart (el otro gran olvidado de la antropología política) se sublevaba también contra la artificiosa demarcación entre economía y ritual en el estudio de las sociedades primitivas. Más aún, escribía unas frases que no me resisto a transcribir porque son muy semejantes al talante de Mauss y porque constituyen todo un aviso a los estudiosos superespecializados de nuestras sociedades. $\mathrm{Y}$, además, porque me parecen impregnadas de un profundo espíritu lúdicro:

«Es un hecho -escribía Hocart en 1935- que en nuestra comunidad existen gentes que han reducido su búsqueda del bienestar a la compra y venta de acciones, mientras otros han reducido su interés al ceremonial eclesiástico. Esto abre la posibilidad de que unos teóricos se dediquen a estudiar especialmente la economía mientras otros se especializan en el ritual. Aun así, a uno le queda la duda de que esto sea acertado, y seguramente nuestros economistas se habrían visto menos embrollados por los acontecimientos que se han producido desde 1914 si no hubieran separado la economía de la vida en general tan completamente como lo han hecho» ${ }^{59}$.

Porque ensanchar el universo del discurso no tiene por qué llevar aparejado - ya lo he apuntado al principio- el alimentar esas ficticias segurida-

${ }^{57}$ Ed. cit., p. 49.

59 Mito, ritual y costumbre. Ensayos heterodoxos, Madrid, Siglo XXI, p. 272, 1975 (e. o. 1952). 
des definitorias en las que suelen instalarse los académicos. Por suerte o por desgracia, lo político, como lo sagrado, parece estar dotado de una inherente ambigüedad. Probablemente, como lo más noble y estrictamente humano. Quién sabe si a eso se refería Mauss cuando recalcaba el doble significado de la palabra don en alemán ( $g i f t$ ): regalo y veneno ${ }^{60}$.

so Sociologie et anthropologie, cit., p. 255. Véase tambiẻn E. Benveniste, op. cit., página 68. F. G. Bailey hace uso de la observación de Mauss para titular, de forma un tanto irónica, un libro compilado por él: Gifts and Poison. The Politics of Reputation, Basil Blackwell, Oxford, 1971. 